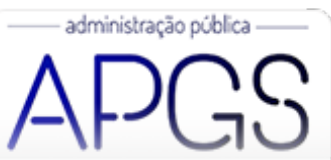

Administração Pública e Gestão Social ISSN: 2175-5787

apgs@ufv.br

Universidade Federal de Viçosa

Brasil

\title{
Gestão Fiscal Municipal: uma análise sob a ótica do federalismo fiscal e dos ciclos políticos nos governos locais
}

Giacomel de Oliveira, Tomas Matheus; Dall'Asta, Denis; Costa da Silva Zonatto, Vinícius; Abilio Martins, Vinicius

Gestão Fiscal Municipal: uma análise sob a ótica do federalismo fiscal e dos ciclos políticos nos governos locais Administração Pública e Gestão Social, vol. 13, núm. 4, 2021

Universidade Federal de Viçosa, Brasil

Disponible en: https://www.redalyc.org/articulo.oa?id=351568433011

\section{(c) (1) $\Theta(9$}

Esta obra está bajo una Licencia Creative Commons Atribución-NoComercial-SinDerivar 3.0 Internacional. 


\title{
Gestão Fiscal Municipal: uma análise sob a ótica do federalismo fiscal e dos ciclos políticos nos governos locais
}

\author{
Municipal Fiscal Management: an analysis from the perspective of fiscal federalism and political cycles in local \\ governments \\ Gestión Fiscal Municipal: un análisis desde la perspectiva del federalismo fiscal y los ciclos políticos en los gobiernos \\ locales
}

Tomas Matheus Giacomel de Oliveira

Universidade Estadual do Oeste do Paraná, Brasil

tomas-matheus@hotmail.com

Denis Dall'Asta

Universidade Estadual do Oeste do Paraná, Brasil

Denis.Asta@unioeste.br

Vinícius Costa da Silva Zonatto

Universidade Federal de Santa Maria, Brasil

viniciuszonatto@gmail.com

Vinicius Abilio Martins

Universidade Estadual do Oeste do Paraná, Brasil

viniciusabilio@gmail.com
Redalyc: https://www.redalyc.org/articulo.oa? id $=351568433011$

Recepción: 26 Enero 2021

Aprobación: 19 Marzo 2021

Publicación: 01 Octubre 2021

\section{Resumo:}

Objetivo da Pesquisa: Analisar os fatores que influenciam a gestão fiscal municipal sob a ótica da teoria do federalismo fiscal e da teoria dos ciclos políticos nos governos locais.

Enquadramento Teórico: Este estudo aborda a gestão fiscal municipal, o federalismo fiscal e os ciclos políticos.

Metodologia: Utilizou-se de modelos de regressão para dados em painéis, nos governos locais representados pelos municípios do Paraná, no período de 2013 a 2019.

Resultados: As variáveis representativas da autonomia arrecadatória influenciam positivamente os índices da dívida consolidada líquida e os gastos com pessoal. Também se identificou que a condição financeira auxilia na explicação dos indicadores da gestão fiscal. Por fim, com base nos ciclos políticos, observa-se uma tendência ao comportamento oportunista nos períodos eleitorais, já que ambos os indicadores tendem a ser maiores nos períodos de eleiçóes locais.

Originalidade: Explorar a gestão fiscal municipal, relacionada às particularidades políticas, fiscais e federativas dos governos subnacionais no cenário paranaense, cujas características de arrecadação e distribuição dos tributos permitem o emprego de diferentes variáveis.

Contribuições teóricas e práticas: A pesquisa apresenta contribuições teóricas e práticas ao retratar os fatores que impactam a gestão fiscal nos governos locais sob a lente das abordagens teóricas do federalismo fiscal e dos ciclos políticos, demonstrando os elementos que podem afetar o equilíbrio das contas públicas.

Palavras-Chave: Gestão Fiscal, Federalismo Fiscal, Ciclos Políticos.

\section{Abstract:}

Research Objective: Analyze the factors that influence municipal fiscal management from the perspective of the theory of fiscal federalism and the theory of political cycles in local governments.

Theoretical Framework: This study addresses municipal fiscal management, fiscal federalism and political cycles. 
Methodology: We used regression models for panel data, in the local governments represented by Paraná municipalities, in the period from 2013 to 2019.

Results: The variables representing the collection autonomy positively influence the indexes of net consolidated debt and personnel expenses. It was also identified that the financial condition helps to explain the indicators of fiscal management. Finally, based on political cycles, there is a tendency towards opportunistic behavior in electoral periods since both indicators tend to be higher during periods of local elections.

Originality: Exploring municipal fiscal management, related to the political, fiscal and federative particularities of subnational governments, in the state of Paraná scenario, whose characteristics of collection and distribution of taxes, allows the use of different variables.

Theoretical and practical contributions: The research presents theoretical and practical contributions by portraying the factors that impact fiscal management in local governments, under the lens of theoretical approaches to fiscal federalism and political cycles, demonstrating the elements that can affect the balance of public accounts.

KEYWORDs: Fiscal Management, Fiscal Federalism, Political Cycles.

\section{ReSUMEN:}

Objetivo de la investigación: Analizar los factores que influyen en la gestión fiscal municipal desde la perspectiva de la teoría del federalismo fiscal y la teoría de los ciclos políticos en los gobiernos locales.

Marco teórico: Este estudio aborda la gestión fiscal municipal, el federalismo fiscal y los ciclos políticos.

Metodología: Utilizamos modelos de regresión para datos de panel, en los gobiernos locales representados por los municipios de Paraná, en el período de 2013 a 2019.

Resultados: Las variables que representan la autonomía de cobranza influyen positivamente en los índices de endeudamiento neto consolidado y gastos de personal. También se identificó que la condición financiera ayuda a explicar los indicadores de la gestión fiscal. Finalmente, con base en los ciclos políticos, existe una tendencia al comportamiento oportunista en los períodos electorales, ya que ambos indicadores tienden a ser más altos durante los períodos de elecciones locales.

Originalidad: Explorar la gestión fiscal municipal, relacionada con las particularidades políticas, fiscales y federativas de los gobiernos subnacionales en el escenario de Paraná, cuyas características de recaudación y distribución de impuestos, permite el uso de diferentes variables.

Aportes teóricos y prácticos: La investigación presenta contribuciones teórico y prácticas al retratar los factores que impactan la gestión fiscal en los gobiernos locales, bajo la óptica de enfoques teóricos del federalismo fiscal y los ciclos políticos, demostrando los elementos que pueden afectar el equilibrio de las cuentas públicas.

Palabras Clave: Gestión Fiscal, Federalismo fiscal, ciclos políticos.

\section{INTRODUÇÃo}

Para uma gestão fiscal responsável e com equilíbrio das contas públicas é pertinente observar a responsabilidade na execução dos gastos públicos, o planejamento, a transparência e o controle na gestão (Cruz \& Afonso, 2018). Neste sentido, as características relacionadas à arrecadação das receitas, a descentralização fiscal, a composição das despesas e os elementos políticos e eleitorais contribuem para manter o equilíbrio das contas públicas (Sáez, 2014; Grisorio \& Prota, 2015; Suzart, Zuccolotto, \& Rocha, 2018).

No contexto da teoria do federalismo fiscal, o fornecimento de bens e serviços é limitado à jurisdição dos entes públicos. Ao observar o cenário brasileiro, as complexas normativas tributárias fazem com que os governos locais não tenham condições necessárias e nem suficientes para atender os anseios da população local, sendo em diversas vezes extremamente dependentes das transferências intergovernamentais, para manutenção de suas atividades e oferta de bens e serviços aos cidadãos (Suzart et al., 2018).

Após a primeira geração da teoria do federalismo, a segunda geração deixa de preocupar-se apenas com os fatores econômicos, passando a abrir o leque para outras abordagens, como a abordagem política (Oates, 2005). Tal abordagem pode ser entendida por meio da teoria dos ciclos políticos, que, segundo Vicente e Nascimento (2012), tratam justamente dos interesses eleitoreiros dos gestores na gestão dos entes públicos.

Assim, as estruturas quanto ao federalismo fiscal e os ciclos políticos e orçamentários potencialmente afetam a gestão fiscal responsável nos entes, relacionadas a despesas com pessoal, aquisição de dívida pública e alocação de recursos de forma consciente em áreas de amplo interesse social (Cavalcante, 2016; 
Caldeira, Wilbert, Moreira, \& Serrano, 2016; Segatto \& Abrucio, 2018). Destarte, uma boa gestão fiscal tende a impactar no desenvolvimento socioeconômico dos entes públicos (Louzano, Abrantes, Ferreira, \& Zuccolotto, 2019).

O estudo de Suzart, Zuccolotto e Rocha (2018) trata da temática do federalismo fiscal nos municípios brasileiros e demonstra a relevância de incluir novas variáveis na discussão da teoria. Já os estudos de Gonçalves, Funchal e Bezerra (2017) e Gerigk e Ribeiro (2018) evidenciam que fatores políticos têm potencial de interferir na gestão dos gastos públicos. Além disso, Louzano, Abrantes, Ferreira, e Zuccolotto (2019) e Silva e Crisóstomo (2019) observam fatores associados à gestão fiscal municipal. Contudo, tais variáveis têm sido observadas de maneira isolada nestas investigações. Assim, a discussão da presente pesquisa avança na busca por empregar a análise de diferentes elementos de forma conjunta e num cenário específico.

Desta forma, o estudo avança observando a análise do grau de dependência com base na estrutura, de maneira segregada, envolvendo as características específicas de distribuição. $\mathrm{O}$ estudo também inova ao analisar especificamente os municípios paranaenses, pois, além de permitir a análise da diversidade quando a condição financeira, do porte e de características socioeconômicas, pode-se compreender diferentes modelos de transferências intergovernamentais, aspectos marcantes do federalismo fiscal. O estado do Paraná adota o modelo devolutivo, ou seja, parte do tributo retorna para o município de ocorrência do fato gerador, diferente do modelo distributivo adotado pela União, cujas fórmulas incluem indicadores demográficos e socioeconômicos (Baião, Cunha, \& Souza, 2017).

Diante dos estudos que embasam a discussão e problemática proposta é pertinente destacar a relevância de se explorar os referidos temas nos governos subnacionais, que são os principais responsáveis pela gestão e alocação dos recursos públicos. Desta forma, com este estudo pretende-se responder a seguinte questão de pesquisa: Quais os fatores que influenciam a gestão fiscal municipal, sob a ótica do federalismo fiscal e ciclos políticos?

Para tanto, o objetivo geral da pesquisa é analisar os fatores que influenciam a gestão fiscal municipal sob a ótica da teoria do federalismo fiscal e da teoria dos ciclos políticos nos governos locais. Assim, inicialmente, pretende-se verificar os principais indicadores do federalismo fiscal, ciclos políticos e gestão fiscal, para que se possa analisar descritivamente essas variáveis e, posteriormente, avaliar a influência das variáveis representativas do federalismo fiscal e ciclos políticos nos índices de gestão fiscal dos governos locais.

O estudo é relevante para o aprofundamento das pesquisas contábeis na área pública, buscando compreender a realidade fiscal dos municípios que afetam a gestão dos entes. Além disso, contribui para a evidenciação dos fatores que impactam a gestão fiscal responsável que permitem o controle das contas públicas. Com isso, gestores e sociedade podem visualizar quais as políticas mais adequadas, quanto à arrecadação e distribuição dos recursos para melhor oferta de bens e serviços para a população local.

\section{Aporte Té́RICo E HIPóteses DA PESQUisa}

A ideia central oriunda das discussóes da teoria do federalismo fiscal contempla fatores da economia e política, que presumem que a oferta de bens e serviços públicos à população é diretamente afetada pelas características arrecadatórias, notadamente modelos centralizados ou descentralizados de arrecadação e distribuição dos recursos arrecadados entre governos multiníveis (Oates, 2005; Brueckner, 2006; Weingast, 2006).

No Brasil, a promulgação da Constituição Federal em 1988 estabeleceu uma nova era para o federalismo brasileiro. Os entes subnacionais passaram a exercer poderes mais significativos, deixando de concentrar-se na União. Também a autonomia política e administrativa dos entes locais parece ter sido resolvida, e estes passaram a ter relevante papel na oferta de bens e serviços públicos (Suzart et al., 2018).

O modelo de federalismo fiscal onde se observa a distribuição de competência entre o governo central e governos locais reflete num processo de descentralização (Caldeira et al., 2016). Assim sendo, o federalismo 
fiscal brasileiro pode ser compreendido como a combinação entre a autonomia e interdependência (Segatto \& Abrucio, 2018).

Outra teoria que contribui para esta pesquisa, bastante difundida na literatura sobre a gestão pública, é a chamada teoria das escolhas públicas, inicialmente discutidas por autores como James Buchanan e Joseph Schumpeter (Oliveira \& Carvalho, 2009). Uma crença comum observada na literatura é que os resultados macroeconômicos são determinantes dos resultados eleitorais, já que os governantes direcionam suas políticas para sua preferência de manter-se no cargo (Castro \& Martins, 2018).

Estudos anteriores como os de Grisorio e Prota (2015), Borger e Proost (2016), Kuhlmey e Hintermann (2019) e os estudos nacionais como os de Vieira, Abrantes, Ferreira e Lopes (2017) e Suzart, Zuccolotto e Rocha (2018), relacionaram a questão da descentralização fiscal e autonomia arrecadatória, com diferentes variáveis da gestão pública, com vistas a aprimorar as discussões a respeito do federalismo fiscal.

Relacionada à discussão do federalismo fiscal, tem-se a discussão sobre a condição financeira governamental, conforme discutida em estudos como os de Winarna, Widagdo e Setiawan (2017), LópezHernandez, Zafra-Gómez, Plata-Días e Higuera-Molina (2018) e Dantas, Diniz e Lima (2019). Tais estudos permitem a compreensão do impacto da condição financeira governamental para a gestão dos entes públicos.

No que se refere aos ciclos políticos, estudos como os de Vicente e Nascimento (2012), Sáez (2014), Castro e Martins (2018), Sidorkin e Vorobyev (2018) e outros evidenciam que os interesses políticos e eleitorais dos gestores determinam o seu comportamento e impactam na gestão dos recursos públicos e, consequentemente, nos indicadores de gestão.

De modo geral, percebe-se que as diferentes abordagens teóricas utilizadas na literatura para investigar tais aspectos têm-se dedicado a promover análises específicas e observando os efeitos diretos entre tais relações. Contudo, há necessidade de se promover investigações mais amplas, com o intuito de melhor compreensão de suas interações e efeitos nas escolhas dos gestores em relação à definição de políticas públicas e a aplicação dos recursos. É neste contexto que se insere a análise proposta, que investiga a gestão fiscal municipal sob a ótica do federalismo fiscal e dos ciclos políticos nos governos locais.

Um importante instrumento de gestão nos governos locais que pode ser influenciado pelos elementos teóricos descritos está relacionado à responsabilidade na gestão fiscal, conforme previsto pela Lei Complementar n. 101 de 2000 (Lei de Responsabilidade Fiscal, 2000). O estudo de Cruz e Afonso (2018) apresenta os pilares da gestão fiscal, relacionando os indicadores de cumprimento de metas e limites fiscais com as variáveis de planejamento, transparência e controle. Contudo, os resultados encontrados apresentaram baixa associação, o que, segundo os autores, tende a estar relacionado aos diferentes incentivos dos gestores em cumprir limites e metas e atender aos outros pilares.

Um dos pilares da gestão fiscal municipal bastante explorado nos estudos nacionais, é o da responsabilidade no cumprimento dos limites (Cruz \& Afonso, 2018). O cumprimento dos limites e metas da gestão fiscal, que compreendem a base da responsabilidade fiscal, em geral, são obtidos através de aspectos quantitativos, conforme determinado na Lei de Responsabilidade Fiscal (Cruz \& Afonso, 2018).

As variáveis admitidas para medir a gestão fiscal municipal e que potencialmente são afetadas pelo federalismo fiscal e por fatores políticos seguem os pilares da responsabilidade na gestão fiscal expostos por Cruz e Afonso (2018), representando os limites impostos pela LRF para equilíbrio das contas públicas. Assim, determinou-se para a pesquisa os índices de despesa com pessoal (IGP) (Macedo \& Corbari, 2009; Linhares, Penna, \& Borges, 2013) e o índice da dívida consolidada líquida (IDCL) (Lazarin, Mello, \& Bezerra, 2014; Correia \& Neduziak, 2017) como elementos de análise da gestão fiscal.

Estudos internacionais como os de Sobel, Dutta e Roy (2012), Grisorio e Prota (2015), Terman e Feiock (2016), Park (2017), Fan, Wu, Wu e Wang (2018), Vidoli e Fusco (2018) e Garcia-Milà, McGuire e Oates (2018) destacaram fatores orçamentários, especialmente relacionados à arrecadação tributária, como aspectos centrais da discussão teórica do federalismo fiscal. Pelos estudos é possível observar a influência da descentralização e autonomia arrecadatória na gestão pública nos governos locais. 
No que se refere à teoria dos ciclos políticos, Sáez (2014) destaca que variáveis como os ciclos de orçamentos políticos e a ideologia partidária, alternância de poder e proximidade ideológica entre os governos locais e nacionais impactam diretamente nos gastos com as dívidas subnacionais da nação. No contexto brasileiro, estudos como os de Vicente e Nacimento (2012), Gonçalves et al. (2017) e Louzano et al. (2019) relacionaram indicadores de gestão fiscal com fatores políticos.

Como pode-se verificar, percebe-se que os fatores relacionados à gestão fiscal podem ser impactados por diferentes aspectos do federalismo fiscal e ciclos políticos, como sugerido nas evidências encontradas em estudos anteriores desenvolvidos sobre o tema, tais como Mora e Giambiagi (2007), Sáez (2014), Azevedo, Gatsio, Silva e Lima (2015), Costa, Raupp e Tezza (2017), Castro e Martins (2018), Suzart et al. (2018), Segatto e Abrucio (2018) e outros. Diante disso, formula-se a hipótese central norteadora da pesquisa:

Hipótese H.: Os índices de gestão fiscal municipal são influenciados pelas variáveis do federalismo fiscal e dos ciclos políticos.

Para uma avaliação adequada dos resultados da pesquisa, considerando as diferentes variáveis de análise relacionadas ao federalismo fiscal e os ciclos políticos e seus efeitos nas diferentes variáveis que analisam a gestão fiscal municipal, segrega-se a hipótese central de pesquisa de acordo com as duas variáveis de análise admitidas para representar a gestão fiscal municipal, de modo que se possa identificar os melhores preditores para cada um destes elementos de análise.

O índice de despesa com pessoal determina a responsabilidade dos gastos públicos com pessoal de acordo com os pressupostos da lei de responsabilidade fiscal, evidenciando o quanto da Receita Corrente Líquida (RCL) é comprometido para despesas com pessoal (Macedo \& Corbari, 2009, Linhares et al., 2013). Sendo assim, Hipótese 1a (H1a) estabelece que:

$\mathrm{H}_{1 \mathrm{a}}$ : $\mathrm{O}$ índice de gasto com pessoal é influenciado pelas variáveis do federalismo fiscal e dos ciclos políticos.

Outro índice utilizado nesta pesquisa para análise da gestão fiscal municipal é o da dívida consolidada líquida, já que regras e limites para coibir o endividamento desordenado são importantes para melhorar a gestão dos recursos públicos (Carvalho, Oliveira, \& Santiago, 2010). Estudos como os de Lazarin, Mello e Bezerra (2014) e Correia e Neduziak (2017) destacam a importância de investigar essa variável representativa da gestão fiscal responsável. A partir destas evidências, a Hipótese $\mathrm{H} 1 \mathrm{~b}(\mathrm{H} 1 \mathrm{~b})$ estabelece que:

$\mathbf{H}_{1 \mathrm{~b}}$ : O índice da dívida consolidada líquida é influenciado pelas variáveis do federalismo fiscal e dos ciclos políticos.

Diante do exposto, destaca-se a seguir os procedimentos metodológicos adotados para a pesquisa.

\section{Procedimentos Metodológicos}

O estudo classifica-se quanto ao seu delineamento como uma pesquisa descritiva, documental e quantitativa (Raupp \& Beuren, 2009). Para tanto, selecionaram-se os municípios paranaenses, já que a teoria do federalismo fiscal requer esse aprofundamento na discussão em governos locais (Oates, 2005).

Para coleta de dados, utilizaram-se os demonstrativos contábeis e de gestão fiscal dos entes analisados, disponíveis nos sites do Tribunal de Contas do Estado do Paraná (TCE-PR), os dados relativos aos pleitos eleitorais, disponíveis no site do Tribunal Superior Eleitoral (TSE) e dados de pesquisas socioeconômicas realizadas pelo Instituto Brasileiro de Geografia e Estatística (IBGE). A coleta de dados contempla a análise de informações de todos os 399 municípios do Estado do Paraná, abrangendo como período de análise os exercícios de 2013 a 2019.

Após a coleta, os dados foram tabulados e as variáveis calculadas com a utilização de planilhas eletrônicas e softwares estatísticos (Office Excel e Stata ${ }^{\circ}$ ), assim como para realização das análises dos resultados. As variáveis utilizadas na pesquisa com as respectivas descrições e fontes são apresentadas no Quadro 1.

Quadro 1 - Variáveis da pesquisa 
Quadro 1 - Variáveis da pesquisa

\begin{tabular}{|c|c|c|c|c|}
\hline $\begin{array}{l}\text { Grupo da } \\
\text { Variável }\end{array}$ & \multicolumn{2}{|c|}{ Variável } & Descrição & Fonte \\
\hline \multirow[t]{2}{*}{$\begin{array}{l}\text { Gestão Fiscal } \\
\text { Municipal }\end{array}$} & \multicolumn{2}{|l|}{ IGP } & $\begin{array}{l}\text { Índice de Gastos pessoal: relação entre os gastos } \\
\text { com pessoal e a RCL. }\end{array}$ & \multirow{2}{*}{$\begin{array}{l}\text { Macedo } \\
\text { Corbari (2009) } \\
\text { Carvalho, } \\
\text { Oliveira } \\
\text { Santiago (2010) } \\
\text { Brasil }(2000)\end{array}$} \\
\hline & \multicolumn{2}{|c|}{ IDCL } & $\begin{array}{l}\text { Dívida Consolidada Líquida: percentual da dívida } \\
\text { consolidada líquida em relação à RCL. }\end{array}$ & \\
\hline \multirow{4}{*}{$\begin{array}{l}\text { Fed } \\
\text { Federalismo } \\
\text { Fiscal } \\
\text { (Autonomia } \\
\text { Arrecadatória) }\end{array}$} & \multirow[t]{3}{*}{ GD } & FPM & $\begin{array}{l}\text { Grau de Dependência - Fundo de Participação dos } \\
\text { Municípios }\end{array}$ & \multirow{4}{*}{$\begin{array}{l}\text { Adaptado de } \\
\text { Araújo e Paes } \\
(2015) \\
\text { Caetano, Ávila } \\
\text { Tavares (2017) } \\
\text { Macedo } \\
\text { Corbari (2009) }\end{array}$} \\
\hline & & Trans_Est & Grau de Dependência - Transferências Estaduais & \\
\hline & & D_Trans & Grau de Dependência - Demais Transferência & \\
\hline & \multicolumn{2}{|l|}{ IRT } & $\begin{array}{l}\text { Índice da Receita Tributária própria: indica o } \\
\text { quanto da receita corrente é oriunda de receitas } \\
\text { tributárias próprias. }\end{array}$ & \\
\hline \multirow{3}{*}{$\begin{array}{l}\text { Fed- } \\
\text { Federalismo } \\
\text { Fiscal } \\
\text { (Condição } \\
\text { Financeira) }\end{array}$} & \multicolumn{2}{|l|}{ NR } & $\begin{array}{l}\text { Necessidade de Recursos: relação entre a diferença } \\
\text { do passivo financeiro e o ativo financeiro, com a } \\
\text { receita corrente líquida. }\end{array}$ & \multirow{3}{*}{$\begin{array}{l}\text { Souza et al. } \\
(2015) \text {. Winarna } \\
\text { et al. (2017) } \\
\text { López- } \\
\text { Hernandez et al. } \\
(2018)\end{array}$} \\
\hline & \multicolumn{2}{|l|}{ RR } & $\begin{array}{l}\text { Realização da Receita: indica a relação existente } \\
\text { entre as receitas totais orçadas e arrecadadas. }\end{array}$ & \\
\hline & \multicolumn{2}{|c|}{ EDC } & $\begin{array}{l}\text { Execução da despesa corrente: indica a relação } \\
\text { entre as despesas e as receitas correntes. } \\
\text { Demonstrando o excesso de arrecadação corrente. }\end{array}$ & \\
\hline \multirow[t]{3}{*}{$\begin{array}{l}\text { CP - Ciclos } \\
\text { Politicos }\end{array}$} & \multicolumn{2}{|c|}{ IdPart. } & $\begin{array}{l}\text { Ideologia Partidária: apresenta a ideologia } \\
\text { partidária do gestor eleito. }\end{array}$ & \multirow{3}{*}{$\begin{array}{l}\text { Sáez, (2014) } \\
\text { Cavalcante } \\
(2016) \text {. }\end{array}$} \\
\hline & \multicolumn{2}{|c|}{ ProxId. } & $\begin{array}{l}\text { Proximidade Ideológica: apresenta se o gestor é ou } \\
\text { não da mesma ideologia partidária do governador e } \\
\text { do presidente da república }\end{array}$ & \\
\hline & \multicolumn{2}{|l|}{ Elei } & $\begin{array}{l}\text { Ano eleitoral: variáveis Dummy que representam as } \\
\text { eleições municipais e eleições gerais. }\end{array}$ & \\
\hline $\begin{array}{l}\text { Variáveis de } \\
\text { Controle }\end{array}$ & \multicolumn{2}{|l|}{ ISE } & \multicolumn{2}{|c|}{$\begin{array}{l}\text { Indicadores Socioeconômicos (População, Índice de Desenvolvimento } \\
\text { Humano Municipal (IDHM) e Índice de Gini) }\end{array}$} \\
\hline
\end{tabular}

Fonte: Dados da Pesquisa (2020).

Para análise dos dados, tendo como base os modelos elaborados nos estudos de Macedo e Corbari (2009) e Baldissera, Costa, Dall Asta e Fiirst (2019) e as variáveis de pesquisas descritas no Quadro 1, elaboraramse as seguintes equações para a pesquisa:

Equação 01:

$I D C L_{i t}=\beta 0+F_{i t}+C P_{i t}+I S E_{i t}+\#_{i t}$

Equação 02:

$I G P_{i t}=\beta 0+F e d_{i t}+C P_{i t}+I S E_{i t}+\#_{i t}$

Diante dos modelos apresentados, testou-se a influência das variáveis para a testagem das hipóteses com o uso de Softwares estatísticos, tendo como os pressupostos para a elaboração e análise de modelos para regressão com dados em painel descritas por Maroco (2003), Hair, Anderson, Tatham e Black. (2005) e Greene (2008). Assim, com base nos referidos autores, testaram-se os modelos para efeitos aleatórios, efeitos fixos ou Pooled (Teste F, Breusch/Pagan e Hausman), além dos pressupostos de heterocedasticidade, multicolinearidade e autocorrelação.

Com base nos procedimentos descritos, apresenta-se a seguir a discussão sobre os resultados obtidos com o estudo. 


\section{Análise e Discussão dos Resultados}

Para iniciar a análise dos resultados, com o objetivo de descrever as principais características das variáveis pesquisadas, realizou-se o cálculo da estatística descritiva das variáveis representativas da gestão fiscal e as representativas do federalismo fiscal. A média, desvio padrão, mínimo e máximo de cada uma das variáveis nas 2793 observações realizadas, que representam os indicadores para os 399 municípios no período de 7 anos (2013 a 2019), são apresentados na Tabela 1.

Tabela 1 - Estatística descritiva das variáveis

\begin{tabular}{l|l|lllll}
\hline $\begin{array}{l}\text { Grupo das } \\
\text { Variáveis }\end{array}$ & Variável & Média & $\begin{array}{l}\text { Desv. } \\
\text { Padrăo }\end{array}$ & Mínimo & Máximo & $N^{\circ}$ Obs \\
\hline \multirow{2}{*}{ Dependentes } & IDCL & 0,0364 & 0,134 & $-0,9047$ & 0,8265 & 2793 \\
\cline { 2 - 7 } & IGP & 0,4906 & 0,0462 & 0,1393 & 0,6386 & 2793 \\
\hline \multirow{5}{*}{ Explicativas } & FPM & 0,3905 & 0,133 & 0,0395 & 0,7879 & 2793 \\
& Trasnf_EST & 0,299 & 0,0894 & 0,0582 & 0,9668 & 2793 \\
& D_trasnf & 0,2996 & 0,0583 & 0,0675 & 0,5477 & 2793 \\
& IRT & 0,1019 & 0,0729 & 0,0127 & 0,4733 & 2793 \\
& NR & $-0,6847$ & 0,2377 & $-8,6681$ & 0,7359 & 2793 \\
& RR & 0,9971 & 0,1492 & 0,2805 & 21.481 & 2793 \\
& EDC & 0,9005 & 0,0649 & 0,1852 & 1,1146 & 2793 \\
\hline
\end{tabular}

Fonte: Dados da Pesquisa (2020).

Com base nos dados da Tabela 1 é possível observar uma baixa tendência a dívida consolidada líquida dos municípios analisados, em comparação à RCL, já que os índices de média $(0,0364)$ e desvio padrão $(0,134)$ sugerem tal percepção. Além disso, se observado o limite máximo de 120\%, percebe-se que em nenhuma das observações o limite foi extrapolado.

Contrariamente à IDCL, percebe-se uma tendência a aproximação ao limite máximo de gastos com pessoal (54\%), já que os dados sugerem que os municípios gastam em média $49 \%$ em gastos com pessoal. Destarte, pelo indicador do valor máximo vê-se que houve extrapolação de gastos no conjunto de observações admitidas na pesquisa.

No que se refere aos indicadores de federalismo fiscal, observa-se uma tendência a alto índice de dependência das transferências intergovernamentais, em especial do FPM (39\%) e das transferências oriundas de tributos estaduais (30\%), em comparação ao saldo da RCL. Cabe ressaltar que os saldos de transferências foram observados pelos valores brutos, o que possibilita que a soma das mesmas extrapole 100\% da RCL, que considera as deduções previstas em Lei.

Da condição orçamentária e financeira municipal, pode-se inferir que as receitas tributárias próprias representam pouco mais de $10 \%$ da RCL, que as receitas arrecadadas são superiores às receitas orçadas e que as receitas correntes são suficientes para cobrir as despesas. Destarte, no que se refere a necessidade de recursos municipais, o saldo negativo $(-0,6847)$ sugere que os recursos são suficientes para cobertura dos passivos.

Para suportar a análise sobre a influência das variáveis representativas do federalismo fiscal e dos ciclos políticos sobre os indicadores de gestão fiscal, realizaram-se os testes de regressão com base no modelo proposto. A tabela 2 apresenta os resultados do modelo da regressão e os respectivos pressupostos do modelo. 
Tabela 2 - Análise da Regressão e pressupostos do modelo

\begin{tabular}{|c|c|c|c|c|c|c|c|c|c|}
\hline \multirow{2}{*}{$\begin{array}{l}\text { Variável } \\
\text { dependente } \\
\text { da } \\
\text { regressão }\end{array}$} & \multicolumn{3}{|c|}{$\begin{array}{l}\text { Teste Ef eitos fixos, aleatório e } \\
\text { Pooled }\end{array}$} & \multicolumn{3}{|c|}{ Pressupostos } & \multicolumn{3}{|c|}{ Relevância do modelo } \\
\hline & $F$ test & Breusch-Pagan & Hausman & $\begin{array}{l}\text { White } \\
\text { Test }\end{array}$ & $\begin{array}{l}\text { Mean } \\
\text { VIF }\end{array}$ & Durbin-Watson & $\begin{array}{l}\text { Prob }> \\
F\end{array}$ & $R 2$ & obs. \\
\hline $\begin{array}{l}\text { IDCL } \\
\text { IGP }\end{array}$ & $\begin{array}{l}0.0000 \\
0.0000\end{array}$ & $\begin{array}{l}0.0000 \\
0.0000\end{array}$ & $\begin{array}{l}0.0000 \\
0.0000\end{array}$ & $\begin{array}{l}5.5 e-59 \\
12 e-77\end{array}$ & $\begin{array}{l}2.10 \\
210\end{array}$ & $\begin{array}{l}1,954 \\
1846\end{array}$ & $\begin{array}{l}0.0000 \\
0.0000\end{array}$ & $\begin{array}{c}0.1021 \\
0.2235\end{array}$ & $\begin{array}{l}2793 \\
2793\end{array}$ \\
\hline
\end{tabular}

Fonte: Dados da Pesquisa (2020).

Para ambos os modelos, os resultados foram significativos a 1\%, com R2 de 0,1021 e 0,2235, respectivamente para IDCL e IGP. Tal resultado demonstra que o modelo pode ser utilizado para explicar tais variáveis. Com base nos testes F test, Breusch-Pagan e Hausman, os resultados direcionam para a utilização da modelagem de efeitos fixos como mais adequado.

Com relação aos pressupostos do modelo, o teste White sugere problemas de heterocedasticidade, sendo assim, foi utilizada a correção robusta para mitigar os referidos impactos na análise. Já os testes de Durbin-Watson e Mean VIF apontam que os modelos não apresentaram, respectivamente, problemas de autocorrelação e multicolinearidade.

A Tabela 3 apresenta os resultados da regressão para a variável dependente de dívida consolidada, tendo como variáveis explicativas as representativas do federalismo fiscal e dos ciclos políticos, além das variáveis socioeconômicas. Os resultados apresentados na tabela são pertinentes para a análise da relação entre a autonomia arrecadatória, condição financeira e fatores políticos e (ou) eleitorais sobre os níveis de dívida municipal.

Tabela 3 - Influência das variáveis explicativas no índice da dívida consolidada líquida

\begin{tabular}{|c|c|c|c|c|c|c|}
\hline IDCL & Coef. & Std. Err. & $\mathbf{t}$ & $\mathbf{P}>|\mathbf{t}|$ & \multicolumn{2}{|c|}{ [95\% Conf. Interval] } \\
\hline FPM & 0.2898588 & 0.0657078 & 4.41 & 0.000 & 0.1610177 & 0.4186999 \\
\hline T_Est & 0602548 & 0.0646052 & 0.93 & 0.351 & -0.0664244 & 0.1869339 \\
\hline D_Transf. & 0.3391981 & 0.0870175 & 3.90 & 0.000 & 0.1685725 & 0.5098237 \\
\hline IRT & 0.1585559 & 0.1164742 & 1.36 & 0.174 & -0.0698288 & 0.3869406 \\
\hline NR & 0.0624711 & 0.0422376 & 1.48 & 0.139 & -0.0203491 & 0.1452914 \\
\hline $\mathrm{RR}$ & -0.0197065 & 0.0150865 & -1.31 & 0.192 & -0.0492884 & 0.0098754 \\
\hline $\mathrm{EDC}$ & 0.2961056 & 0.0408096 & 7.26 & 0.000 & 0.21 & 0.3761259 \\
\hline Elei & 0.0117911 & 0.0059529 & 1.98 & 0.048 & 0.0001185 & 0.0234638 \\
\hline lei_G & -0.0260793 & 0.0059232 & -4.40 & 0.000 & -0.0 & 4649 \\
\hline P_Est & -0.0021575 & 0.0045784 & -0.47 & 0.638 & -0.0 & 88199 \\
\hline P_Fed & -0.0041866 & 0.0048961 & -0.86 & 0.393 & -0.013787 & 0.0054138 \\
\hline DHM & 0287371 & 0.0976567 & 0.29 & 0.769 & -0.1627499 & 0.2202241 \\
\hline Gini & -0.0859911 & 0.0478145 & -1.80 & 0.072 & -0.1797466 & 0.0077645 \\
\hline Log_POP & 0.0276946 & 0.0054375 & 5.09 & 0.000 & 0.0170326 & 0.0383565 \\
\hline Cons & -0.6845753 & 0.1280789 & -5.34 & 0.000 & -0.9357148 & -0.4334357 \\
\hline
\end{tabular}

Fonte: Dados da Pesquisa (2020).

Das variáveis representativas das dependências de transferências intergovernamentais, percebe-se que as transferências oriundas do Fundo de Participação dos Municípios impactam significativamente (1\%) e de forma positiva os indicadores da dívida consolidada municipal. Os resultados demonstram que o coeficiente da regressão associado aos parâmetros da variável é de 0,2898588 , ou seja, quanto maior a dependência das transferências do FPM maior é a tendência de manutenção da dívida consolidada pelos governos locais.

Igualmente às transferências oriundas do FPM, pode-se perceber que as demais transferências (exceto cotas partes dos impostos estaduais) também foram significativas (1\%) e positivas, associadas aos indicadores da dívida consolidada. O coeficiente associado aos parâmetros da regressão para a referida variável é de 
0.3391981, demonstrando que os aumentos na dependência de transferências intergovernamentais tendem a aumentar a dívida consolidada líquida dos governos locais.

Com base nos pressupostos do federalismo fiscal, pode-se inferir que um modelo descentralizado possui características e problemas que podem ser evidenciados, em especial, para alocação de recursos para fornecer níveis mínimos de bens e serviços, conforme destacado por Grisorio e Prota (2015) e Kuhlmey e Hintermann (2019). Isto pode ser agravado no modelo federativo brasileiro, já que, conforme pressupõem os estudos de Segatto e Abrucio (2018) e Suzart et al. (2018), existe uma dependência de transferências intergovernamentais. Tais fatores tendem a representar uma propensão para alavancar o endividamento local, conforme visto nos achados do presente estudo.

Com relação às variáveis representativas da condição financeira municipal, percebe-se que as variáveis representativas da necessidade de recursos e do planejamento das receitas orçamentárias não foram significativas para explicar a dívida consolidada líquida. Diferente das demais variáveis, os parâmetros associados aos indicadores de execução orçamentária impactam positivamente, sendo significativa ao nível de $1 \%$ a dívida consolidada líquida dos entes analisados. Assim, percebe-se que o coeficiente associado aos parâmetros da variável, (0.2961056), demonstra que maiores níveis de despesas tendem a aumentar a necessidade de dívidas dos governos locais.

O estudo de Lazarin et al. (2014) destaca, com base em seus achados, que o endividamento municipal pode ser uma importante ferramenta para garantir a qualidade de vida da população. Contudo, Mora e Giambiagi (2007) destacam que o enquadramento em busca pelo equilíbrio das contas depende das imposições legais, e Costa et al. (2017) destacam que, ainda que cumpra os limites, esse indicador não é suficiente para o equilíbrio das contas públicas. Tais elementos justificam os achados do presente estudo, já que municípios com maior grau de dependência das transferências e com maior representatividade das despesas sobre as receitas tendem a apresentar valores mais elevados da dívida.

Das variáveis políticas e eleitorais observadas na pesquisa, apenas as representativas dos períodos eleitorais (eleições municipais e eleições gerais) apresentaram-se significativas para explicar os índices da dívida. O alinhamento partidário com os governos estaduais ou federais não apresentaram coeficientes significativos, não impactando na dívida consolidada líquida municipal.

Com relação às eleições municipais, percebe-se que os indicadores foram significativos (5\%) e positivos, demonstrando que os parâmetros associados à variável impactam de maneira positiva a dívida consolidada líquida municipal. Com base nesse resultado é possível evidenciar que no período eleitoral os gestores tendem a aumentar os índices da dívida consolidada líquida municipal no montante representativo do coeficiente da regressão associada ao parâmetro da variável binária (0.0117911).

Diferente das eleições municipais, nos períodos das eleições gerais (majoritárias) há uma tendência para a redução da dívida consolidada líquida nos governos locais, já que os coeficientes associados aos parâmetros da variável binária representativa destes períodos foram de -0.0260793 (significativo a 1\%). Assim, é possível verificar que os gestores busquem menores índices de dívida em períodos de eleições majoritárias, se comparados aos demais períodos.

Percebe-se, assim, que nos anos de eleições gerais não há maiores interesses em contratação de dívida consolidada, embora pudesse haver o interesse na eleição de algum correligionário político em níveis estaduais ou federais. Como o ano das eleições gerais representa um período intermediário do ciclo político local, observa-se que os gestores buscam manter menores índices de dívida consolidada aumentando-a nos períodos mais próximos das eleições locais.

Observados sob a ótica dos ciclos políticos, pode-se ressaltar, igualmente à discussão proposta por Sáez (2014), que destaca a relação de fatores políticos com as dívidas subnacionais, assim como estudos nacionais como os Gonçalves et al. (2017) e Louzano et al. (2019), que evidenciaram a associação de fatores políticos à gestão fiscal, que os municípios tendem a alavancar as dívidas nos períodos eleitorais locais para obter 
seus objetivos. Ressalva-se, porém, que no estudo de Sáez (2014), o impacto era evidenciado também pelo alinhamento partidário, diferente dos resultados aqui encontrados.

Igualmente, a análise dos fatores que impactam os índices de dívida consolidada líquida municipal, a fim de se observar o impacto das variáveis de federalismo fiscal e ciclos políticos em indicadores da gestão fiscal, foi testada a influência das variáveis explicativas (federalismo e ciclos políticos) no índice de gasto com pessoal nos governos locais.

Os resultados da regressão representativos desta relação são apresentados na Tabela 4. A tabela possui informações sobre a influência das variáveis de grau de dependência, condição financeira e ciclos políticos, além das variáveis socioeconômicas, no gasto com pessoal, conforme apresentado a seguir.

Tabela 4 - Influência das variáveis explicativas no índice de gasto com pessoal

\begin{tabular}{l|l|l|l|l|ll}
\hline IGP & Coef. & Std. Err. & T & P $>|t|$ & {$[95 \%$ Conf. Interval] } \\
\hline FPM & 0.1547595 & .0161727 & 9.57 & 0.000 & .1230479 & .1864712 \\
T_Est & 0.1271467 & .0161997 & 7.85 & 0.000 & .0953821 & .1589112 \\
D_Transf. & 0.1528079 & .0216175 & 7.07 & 0.000 & .1104199 & .195196 \\
IRT & 0.1945173 & .0263183 & 7.39 & 0.000 & .1429118 & .2461228 \\
NR & 0.0115723 & .0027574 & 4.20 & 0.000 & .0061654 & .0169791 \\
RR & 0.0205295 & .0065724 & 3.12 & 0.002 & .0076423 & .0334167 \\
EDC & 0.2239793 & .0180083 & 12.44 & 0.000 & .1886682 & .2592904 \\
Elei & 0.0065204 & .0022382 & 2.91 & 0.004 & .0021317 & .0109091 \\
Elei_G & -0.0034194 & .0017963 & -1.90 & 0.057 & -.0069417 & .0001028 \\
AP_ESt & 0.001459 & .0018632 & 0.78 & 0.434 & -.0021943 & .0051123 \\
AP_Fed & 0.0013651 & .0019472 & 0.70 & 0.483 & -.002453 & .0051832 \\
IDHM & -0.0792971 & .0272674 & -2.91 & 0.004 & -.1327635 & -.0258307 \\
Gini & -0.0670187 & .0147231 & -4.55 & 0.000 & -.0958879 & -.0381494 \\
Log_POP & 0.008791 & .0017965 & 4.89 & 0.000 & .0052684 & .0123136 \\
ConS & 0.1104187 & .0374912 & 2.95 & 0.003 & .0369054 & .1839321 \\
\hline
\end{tabular}

Fonte: Dados da Pesquisa (2020).

Com relação às variáveis testadas no modelo, observa-se que todas as variáveis representativas do grau de dependência e autonomia arrecadatória apresentaram coeficientes significativos e positivos para explicar o índice de gasto com pessoal. As variáveis testadas foram o grau de dependência de transferências do fundo de participação municipal, transferências estaduais (cota-parte ICMS e IPVA) e demais transferências intergovernamentais, além do índice de receita tributária.

O FPM foi significativo ao nível de 1\%, com o coeficiente associado aos parâmetros da variável, representativo de 0,1547595 , demonstrando que quanto maior a representatividade do fundo de participação na receita corrente líquida, maior a tendência de gastos com pessoal.

Igualmente ao que foi observado para o FPM, no que se refere às transferências estaduais, relativas à soma da cota-parte do ICMS e IPVA, percebe-se que os parâmetros associados ao grau de dependência dessas transferências foi significativo a $1 \%$ e com coeficiente positivo (0.1271467), assim, sugere-se que o aumento na arrecadação dos tributos estaduais e consequentemente o aumento no repasse, tende a aumentar a destinação de recursos para manutenção de gastos com pessoal.

Com relação às transferências intergovernamentais, não classificadas nos itens anteriores, pode-se perceber comportamento similar às demais, sendo significativas a $1 \%$ e com coeficiente positivo (0.1528079). Com isso, pode-se afirmar que o grau de dependência influencia positivamente o indicador de gasto com pessoal, independente da origem dos recursos e da forma de distribuição destas transferências.

No que concerne à autonomia arrecadatória tributária, contrariamente ao esperado, a mesma apresentou comportamento similar aos índices de grau de dependência, uma vez que o coeficiente foi significativo a $1 \%$ e apresentou relação positiva com o índice de gasto com pessoal. Assim, percebe-se que o aumento na autonomia arrecadatória de tributo tende a resultar em aumento nos índices de gastos com pessoal. 
O comportamento similar aos indicadores de grau de dependência pode estar associado ao fato de que foram observadas apenas as receitas tributárias municipais, desconsiderando as demais receitas próprias dos entes. Assim, as políticas adotadas nos entes para arrecadação própria, tendem a ser as mesmas adotadas para estímulo à arrecadação de tributos estaduais e federais que retornaram, em partes, como transferências para esses entes.

Com isso, pode-se afirmar que maiores índices de receitas oriundas das receitas tributárias próprias e transferidos pelos demais entes da federação são significativos para explicar os indicadores de gasto com pessoal. Portanto, gestores tendem a comprometer mais seus recursos quando arrecadam mais destas fontes, tendo em vista a segurança e baixa variação quanto ao recebimento dos referidos recursos, em condições normais.

Os estudos associados ao federalismo fiscal, como Oates (2005), Weingast (2006), Borger e Proost (2016) e Suzart et al. (2018), e à condição financeira governamental, como Dantas et al. (2019), López-Hernandez et al. (2018) e Winarna et al. (2017), podem contribuir para a compreensão do comportamento das variáveis, já que as características arrecadatórias tendem a impactar a gestão fiscal municipal, em especial nos índices de gastos, podendo, nos casos de gastos excessivos, ocasionar o estresse fiscal.

Além disso, os achados da presente pesquisa contrariam em partes os resultados do estudo de Azevedo et al. (2015), já que o mesmo concluiu que a variação dos limites de gastos como pessoal não foi causada pela variação das receitas, e as evidências do presente estudo demonstram que os fatores associados à arrecadação são determinantes para os níveis de gastos. Contudo, o referido estudo destaca a relação com os próprios gastos, que pode ser comprovado pelo indicador de despesas (EDC), além de ressaltar que as variações são decorrentes dos atos de gestão.

As variáveis representativas da condição financeira e orçamentária dos entes públicos também foram significativas para explicar o índice de gasto com pessoal, demonstrando que os níveis de necessidade de recursos, a relação entre a receita orçada e a receita arrecada e execução da despesa orçamentária em comparação com as respectivas receitas tendem a impactar os indicadores de gasto com pessoal, ou seja, gastos com pessoal mais elevados tendem a comprometer mais as finanças municipais.

Com relação à variável financeira de necessidade de recursos (NR), observa-se que quanto maior a necessidade de recurso, maior o índice de gasto com pessoal, já que o coeficiente associado à variável NR, significativa a $1 \%$, apresentou influência positiva sobre os gastos com pessoal (0.0115723). Assim, à medida que aumenta a necessidade de recursos para cobertura dos passivos financeiros, tende a observar-se maiores índices de gastos com pessoal nesses municípios.

Tal fato está associado às características e período das variáveis analisadas. Como ambas as variáveis foram analisadas no mesmo exercício financeiro, grandes índices de gastos com pessoal tendem a comprometer as receitas municipais e, consequentemente, o excesso de recursos financeiros tende a ser menor, inclusive os oriundos de exercícios anteriores que poderão ser utilizados para outras finalidades, e assim os recursos correntes podem ser utilizados para fins de gasto com pessoal.

Das variáveis orçamentárias, percebe-se que quando a receita orçamentária é mais próxima do equilíbrio, se comparada à receita arrecadada, ou seja, quando há menos excesso de arrecadação, a tendência é que os índices de gastos com pessoal também sejam maiores. Assim, percebe-se que os parâmetros associados ao índice representativo da relação entre receita orçada e arrecadada (RR) sugere uma relação positiva (0.0205295) significativa a $1 \%$.

Pode-se inferir, a partir desse resultado, que os municípios cuja representatividade da receita orçada seja maior sobre a receita total tendem a possuir maiores indicadores de gastos com pessoal, devido ao fato de que essas despesas são facilmente planejadas com certo grau de confiabilidade e, assim, quanto maior o excesso de arrecadação, maiores as chances de o município alocar recursos para outras áreas, ao passo que quando os valores orçados são maiores, tende a comprometer as finanças e a receita corrente líquida, e, consequentemente, ocasionar maiores índices de gasto com pessoal sobre a RCL. 
Da mesma forma, no que se refere aos índices de execução orçamentária, dos recursos correntes, percebese que quanto maior a representatividade das despesas sobre as receitas correntes, maiores também são os índices de gastos com pessoal. Com base na Tabela 4, é possível perceber que o coeficiente foi de 0.2239793 , significativo a $1 \%$, demonstrando a influência positiva dos parâmetros associados à variável sobre os gastos com pessoal.

Os resultados estão de acordo com o esperado, tendo em vista que, como os gastos com pessoal são caracterizados como despesas correntes, a tendência que os entes públicos que tenham maior representatividade desse tipo de gasto, em detrimento dos gastos de capital financiados por recursos correntes, também realizem maiores níveis de gastos com pessoal. Além disso, pode-se destacar que o aumento das despesas correntes pode ser impulsionado por maiores índices desses gastos.

Já com relação às variáveis dos ciclos políticos, pode-se perceber que apenas as representativas do período eleitoral municipal e das eleiçóes gerais é que foram significativas para explicar os índices de gastos com pessoal. $\mathrm{O}$ alinhamento partidário com os governos estaduais e federais não apresentaram resultados significativos aos níveis admitidos nesta pesquisa, o que pode ser encarado como ausência de influência destas variáveis no índice de gasto com pessoal.

Contudo, quando observados os períodos eleitorais, percebe-se que no ano eleitoral para escolha dos gestores municipais há uma tendência ao aumento dos índices gastos com pessoal nos entes analisados, independente das restrições impostas pela lei de responsabilidade fiscal. Percebe-se na Tabela 4 que o coeficiente foi de 0.0065204 , significativo a $1 \%$.

Embora o resultado do coeficiente associado ao parâmetro seja baixo, percebe-se uma tendência de os municípios alocarem mais recursos para gastos com pessoal nos anos em que ocorrem eleiçóes municipais, com vistas, possivelmente, a garantir apoio para a manutenção do poder para si ou aliado político, o que pode ser explicado com base nos pressupostos da teoria dos ciclos políticos, conforme destacado por estudos como os de Castro e Martins (2018) e Sidorkin e Vorobyev (2018).

Contudo, os resultados contrariam o que pressupóe o estudo de Cavalcante (2015), o qual ressalta que o comprometimento excessivo dos recursos financeiros para gastos com pessoal, embora comum na administração pública, tende a ser mal vistos pelo eleitorado, o que gera um impacto, além da responsabilidade na gestão fiscal prevista em lei, mas também para obtenção de bons resultados eleitorais.

Já a variável representativa do período eleitoral no cenário nacional, ou seja, as eleições relativas aos cargos de nível estadual e federal, apresentou comportamento divergente do período de eleições locais. O coeficiente associado aos parâmetros da variável binária foi de -0034194, significante ao nível de 10\%, demonstrando que a influência deste período é negativa sobre o índice de gasto com pessoal.

Assim, observa-se que a tendência é que no período de eleições nos níveis federais e estaduais, por ser um ano intermediário no ciclo eleitoral municipal, os municípios apresentem menores índices de gastos com pessoal, aumentando nos períodos mais próximos das eleições gerais, igualmente ao que é observado no índice da dívida consolidada líquida. Com isso, infere-se que os aumentos de gasto com pessoal local não é uma variável de interesse, no que se refere aos efeitos nos resultados eleitorais obtidos em outros níveis de governo, o que é evidenciado pelos resultados desta e das variáveis de alinhamento partidário.

Diante dos dados observados nesta pesquisa, seja para a variável de dívida consolidada ou para a variável de índice de gasto com pessoal, observa-se que as variáveis representativas do federalismo fiscal, em especial relacionadas a grau de dependência e autonomia arrecadatória, condição financeira e orçamentária dos governos locais e as representativas dos ciclos políticos, impactam e são capazes de explicar, pelo menos em parte, os indicadores de gestão fiscal municipal.

$\mathrm{Na}$ maioria das variáveis observadas, em ambas as variáveis dependentes representativas da gestão fiscal municipal, o impacto das variáveis explicativas significativas aos níveis admitidos nesta pesquisa foi positivo. Com isso, pode-se confirmar as hipóteses testadas nesta pesquisa, as quais baseadas nos estudos 
previamente pesquisados e descritos na fundamentação teórica e nesta análise destacavam que os indicadores do federalismo fiscal e de ciclos políticos influenciavam os índices de gestão fiscal dos governos locais.

Complementarmente, realizou-se a análise da influência dos indicadores socioeconômicos sobre o índice de gasto com pessoal. Como pode-se observar na Tabela 4, tanto as variáveis representativas do Índice de Desenvolvimento Humano Municipal, Índice de Gini e o Logaritmo natural da população local foram significativos a 1\%, com coeficientes associados aos parâmetros, negativos no caso do IDHM (-0.0792971) e do Índice de Gini (-0.0670187), e positivo no caso do Log_POP (0.008791).

Desta forma, considerando-se que quanto maiores forem os índices socioeconômicos do IDHM e Gini, melhor para a gestão municipal, percebe-se que estes municípios com índices melhores destinam menos recursos para gastos com pessoal e possivelmente destinam mais recursos para aplicação em outras áreas, o que pode refletir positivamente na realização de obras e investimentos, bem como na manutenção ou qualificação de serviços públicos essenciais e demandados pela população. Em contrapartida, municípios com piores resultados socioeconômicos tendem a ter maiores indicadores de gasto com pessoal, o que pode dificultar sua capacidade de realização de investimentos.

\section{Conclusão}

Este estudo teve como objetivo analisar os fatores que influenciam a gestão fiscal municipal sob a ótica da teoria do federalismo fiscal e da teoria dos ciclos políticos nos governos locais. Para tanto, aplicou-se um modelo de regressão com dados em painel, para analisar tais aspectos em uma amostra com municípios do estado do Paraná, num recorte temporal de 7 anos (2013 a 2019), utilizando dados disponibilizados em meio eletrônico.

Para fins de atingir os objetivos da pesquisa fez-se análise da testagem das variáveis explicativas, referentes ao federalismo fiscal e aos ciclos políticos, como determinantes dos indicadores da gestão fiscal municipal, em especial os indicadores da dívida consolidada líquida e gastos com pessoal. Como pôde-se observar, as condições arrecadatórias e financeiras dos governos locais ajudam a explicar os índices de gestão fiscal municipal, já que os resultados dos modelos aplicados sugerem a relação entre essas variáveis.

No que se refere aos ciclos políticos, também foi possível observar a existência da relação de influência das variáveis eleitorais sobre os mesmos índices representativos da gestão fiscal, sendo que o ano eleitoral apresenta influência positiva. Desta forma, é perceptível que a busca pela manutenção do cargo ou a busca por benefícios a um aliado político pode representar impactos nos índices de gestão fiscal, tendendo a manter uma boa imagem frente à população local.

Assim sendo, percebe-se que a hipótese $\mathrm{H} 1$ proposta inicialmente foi comprovada por meio dos modelos propostos, uma vez que as principais variáveis testadas são capazes de explicar os indicadores de gestão fiscal (índice da dívida consolidada líquida e índice de gastos com pessoal) de forma positiva. Especificamente para os índices analisados, percebe-se que no caso dos gastos com pessoal ( $\mathrm{H} 1 \mathrm{~b})$, todos os elementos do federalismo fiscal e condição financeira apresentam influência positiva. No caso da dívida consolidada líquida (H1a), apenas os indicadores do fundo de participação dos municípios, outras transferências e execução da despesa corrente foram capazes de exercer uma influência positiva nesta variável.

Neste contexto, pode-se concluir que tais fatores são preditores da gestão fiscal nos governos locais no período analisado. Com isso, o estudo contribui para a compreensão dos elementos que determinam os bons resultados das finanças públicas ao comprovar que a estrutura arrecadatória e a saúde financeira, assim como fatores políticos e eleitorais dos entes impactam no equilíbrio das contas públicas.

Portanto, gestores públicos poderão se utilizar dos referidos achados para direcionar a alocação dos recursos públicos, ao passo que a sociedade e órgãos de controle social poderão observar os elementos que impactam a boa gestão e permitem uma melhor avaliação sobre a aplicação dos recursos públicos e a qualidade do gasto, uma vez que se reconhece que municípios que apresentam melhor estrutura arrecadatória e condição 
financeira e maiores índices de IDHM e de Gini melhoram sua gestão municipal apresentando menos recursos destinados para gastos com pessoal, reduzindo a dívida e tornando-se mais eficientes na aplicação de recursos em outras áreas, têm mais êxito na geração de benefícios à sociedade.

O estudo limita-se a análise num corte temporal de 7 anos, o que remete a análise de duas gestões distintas, mas com um único período eleitoral local. Assim sendo, os fatores de troca de gestão não foram efetivamente controlados para dois mandatos. Além disso, foram selecionadas algumas das principais variáveis das abordagens descritas na pesquisa para testagem do problema, o que impede a análise a fundo de todos os elementos oriundos da discussão teórica.

Contudo, o rigor metodológico adotado fornece importantes evidências que permitem a reflexão sobre o tema e estimulam a realização de novos estudos uma vez que evidenciam as contribuições teóricas e práticas das abordagens teóricas do federalismo fiscal e dos ciclos políticos, para retratar os fatores que impactam a gestão fiscal nos governos locais. Assim, para futuras pesquisas relacionadas às temáticas estudadas, sugerese que os elementos específicos dos quatro pilares da gestão fiscal sejam relacionados aos pressupostos do federalismo fiscal, com vistas a contribuir com a continuidade dos estudos na área. Além disso, pesquisas futuras podem também focar nos elementos do gasto público e as características arrecadatórias, além de observar os possíveis efeitos dos ciclos políticos e de variáveis sociais nas relações analisadas.

\section{REFERÊNCIAS}

Araújo, J. M., Paes, N. L. (2015). Os Determinantes Institucionais do Esforço Fiscal nos Estados Brasileiros. Planejamento e Politicas Públicas, (45).

Azevedo, R. R., Gatsios, R. C., da Silva, J. M., Lima, F. G. (2015). Determinantes da variação do limite de gastos com pessoal em municípios paulistas. Revista Ambiente Contábil. ISSN 2176-9036, 7(1), 216-232.

Baião, A. L., Cunha, A. S. M. D., Souza, F. S. R. N. D. (2017). Papel das transferências intergovernamentais na equalização fiscal dos municípios brasileiros. Revista Serviço Público, 68 (3), 583-610.

Baldissera, J. F., Costa, R. F. S., Dall'Asta, D., Fiirst, C. (2019). Influência das Características Políticas e Eleitorais Sobre a Abertura de Créditos Adicionais. Revista Contabilidade, Gestão e Governança, 22(1), 101-117. Doi: http://d x.doi.org/10.21714/1984-3925_2019v22n1a6

Borger, B., Proost, S. (2016). The political economy of pricing and capacity decisions for congestible local public goods in a federal state. International Tax and Public Finance, 23(5), 934-959. Doi: https://doi.org/10.1007/s10797 $-015-9388-6$

Brueckner, J. K. (2006). Fiscal federalism and economic growth. Journal of Public Economics, CESifo Working Paper, 90(10-11), 2107-2120. Doi: https://doi.org/10.1016/j.jpubeco.2006.05.003

Caetano, C. C. R., Ávila, L. A. C. D., Tavares, M. (2017). A relação entre as transferências governamentais, a arrecadação tributária própria e o índice de educação dos municípios do estado de Minas Gerais. Revista de Administração Pública, 51(5), 897-916. Doi: https://doi.org/10.1590/0034-7612174433

Caldeira, A. A., Wilbert, M. D., Moreira, T. B. S., Serrano, A. L. M. (2016). Sustentabilidade da dívida estadual brasileira: uma análise da relação dívida líquida e resultado primário. Revista de Administração Pública, 50(2), 285-306. Doi: https://doi.org/10.1590/0034-7612151140

Carvalho, J. R. M., de Oliveira, G. F., Santiago, J. S. (2010). Dívida pública: um estudo de indicadores dos estados nordestinos. Revista Universo Contábil, 6(2), 82-100. Doi: http://dx.doi.org/10.4270/ruc.2010214

Castro, V., Martins, R. (2018). Politically driven cycles in fiscal policy: In depth analysis of the functional components of government expenditures. European Journal of Political Economy, 55, 44-64. Doi: https://doi.org/10.1016/ j.ejpoleco.2017.11.003

Cavalcante, P. (2015). Vale a pena ser um bom prefeito? Comportamento eleitoral e reeleição no Brasil. Opinião Pública, 21(1), 87-104. Doi: http://dx.doi.org/10.1590/1807-019121187 
Tomas Matheus Giacomel de Oliveira, et al. Gestão Fiscal Municipal: uma análise sob a ótica do fed...

Cavalcante, P. (2016). Desempenho fiscal e eleições no Brasil: uma análise comparada dos governos municipais. Revista de Administração Pública-RAP, 50(2), 307-330. Doi: https://doi.org/10.1590/0034-7612146623

Correia, F. M., Neduziak, L. C. R. (2017). Impacto dos gastos em investimento na dívida dos estados brasileiros: uma análise Threshold. Revista Brasileira de Estudos Regionais e Urbanos, 11(2), 193-209.

Costa, C. B., Raupp, F. M., Tezza, R. (2017). Endividamento Público: uma Análise da Dívida Consolidada e dos Resultados Nominal e Primário dos Municípios Catarinenses. Revista Conbecimento Contábil, 5(2). Doi: http s://doi.org/10.31864/rcc.v5i2.2622

Cruz, C. F., Afonso, L. E. (2018). Gestão fiscal e pilares da Lei de Responsabilidade Fiscal: evidências em grandes municípios. Revista de Administração Pública, 52(1), 126-148. Doi: https://doi.org/10.1590/0034-76121658 47

Dantas, A. F. Junior, Diniz, J. A., Lima, S. C. (2019). A Influência do Federalismo Fiscal sobre o Estresse Fiscal dos Municípios Brasileiros. Advances in Scientific and Applied Accounting, 12(3), 62-78. Doi: https://doi.org/10.1 4392/ASAA.2019120304

Fan, Y., Wu, Y., Wu, A. M., Wang, W. (2018). Decentralised governance and empowerment of county governments in China: betting on the weak or the strong? Local Government Studies, 44(5), 670-696.

Garcia-Milà, T., McGuire, T. J., Oates, W. E. (2018). Strength in diversity? Fiscal federalism among the fifty US states. International Tax and Public Finance, 25(4), 1071-1091. Doi: https://doi.org/10.1007/s10797-018-9485-4

Gerigk, W., Ribeiro, F. (2018). Investimentos públicos e fatores políticos nos pequenos municípios brasileiros: o que é relevante? Revista Universo Contábil, 14(4), 68-92. Doi: http://dx.doi.org/10.4270/ruc.2018428

Gonçalves, L. G., Funchal, B., Bezerra, J. E. Filho (2017). A influência dos ciclos políticos nos investimentos públicos em infraestrutura: um estudo nos estados brasileiros no período de 2003 a 2014. Revista de Administração Pública, 51(4), 462-481. Doi: https://doi.org/10.1590/0034-7612156337

Greene, W. H. (2008). The econometric approach to efficiency analysis. The measurement of productive efficiency and productivity growth, 1(1), 92-250.

Grisorio, M. J., \& Prota, F. (2015). The short and the long run relationship between fiscal decentralization and public expenditure composition in Italy. Economics Letters, 130, 113-116. Doi: https://doi.org/10.1016/j.econlet.20 15.03.021

Hair, J. F. Jr., Anderson, R. E., Tatham, R. L., Black, W. C. (2005). Análise multivariada de dados. 5.ed. Porto Alegre: Bookman editora.

Kuhlmey, F., Hintermann, B. (2019). The welfare costs of Tiebout sorting with true public goods. International Tax and Public Finance, 26(5), 1166-1210. Doi: https://doi.org/10.1007/s10797-019-09534-z

Lazarin, M. F., Mello, G. R., Bezerra, F. M. (2014). A relação entre a dívida pública e o desenvolvimento socioeconômico dos municípios paranaenses: evidências para o período de 2002 a 2010. Race: revista de administração, contabilidade e economia, 13(2), 719-736.

Lei de Responsabilidade Fiscal: Lei Complementar n. 101, de 4 de maio de 2000. Brasília: Senado Federal.

Linhares, F., Penna, C., Borges, G. (2013). Os efeitos da Lei de Responsabilidade Fiscal no endividamento dos municípios do Piauí. Revista de Administração Pública, 47(6), 1359-1374. Doi: http://dx.doi.org/10.1590/S0 034-76122013000600002

López-Hernández, A. M., Zafra-Gómez, J. L., Plata-Díaz, A. M., de la Higuera-Molina, E. J. (2018). Modeling fiscal stress and contracting out in local government: The influence of time, financial condition, and the great recession. The American Review of Public Administration, 48(6), 565-583. Doi: https://doi.org/10.1177/027507401769 9276

Louzano, J. P. D. O., Abrantes, L. A., Ferreira, M. A. M., Zuccolotto, R. (2019). Causalidade de Granger do índice de desenvolvimento socioeconômico na gestão fiscal dos municípios brasileiros. Revista de Administração Pública, 53(3), 610-627. Doi: http://dx.doi.org/10.1590/0034-761220180139

Macedo, J. J., Corbari, E. C. (2009). Efeitos da lei de responsabilidade fiscal no endividamento dos municípios brasileiros: uma análise de dados em painéis. Revista Contabilidade \& Finanças, 20(51), 44-60. Doi: http://dx. doi.org/10.1590/S1519-70772009000300004 
Maroco, J. (2003). Análise Estatística: com utilização do SPSS. 2.ed. Edições Silabo, Lda.

Mora, M., Giambiagi, F. (2007). Federalismo e endividamento subnacional: uma discussão sobre a sustentabilidade da dívida estadual. Brazilian Journal of Political Economy, 27(3), 472-494.

Oates, W. E. (1999). An essay on fiscal federalism. Journal of economic literature, 37(3), 1120-1149.

Oates, W. E. (2005). Toward a second-generation theory of fiscal federalism. International tax and public finance, 12(4), 349-373. Doi: https://doi.org/10.1007/s10797-005-1619-9

Oliveira, K. V., de Carvalho, F. A. A. (2009). A contabilidade governamental e o calendário eleitoral: uma análise empírica sobre um painel de municípios do Rio de Janeiro no período 1998-2006. Revista de Contabilidade e Organizações, 3(5), 121-141. Doi: https://doi.org/10.11606/rco.v3i5.34735

Park, S. (2017). Local revenue structure under economic hardship: reliance on alternative revenue sources in California counties. Local Government Studies, 43(4), 645-667. Doi: https://doi.org/10.1080/03003930.2017.1305956

Raupp, F. M; Beuren, I. M. (2009) Metodologia da pesquisa aplicável às ciências sociais. In: Beuren, Ilse M. (org.). Como elaborar trabalhos monográficos em contabilidade: teoria e prática. 3. ed. São Paulo: Atlas.

Sáez, L. (2014). The political budget cycle and subnational debt expenditures in federations: panel data evidence from India. Governance, 29(1), 47-65. Doi: https://doi.org/10.1111/gove.12130

Segatto, C. I., Abrucio, F. L. (2018). Os múltiplos papéis dos governos estaduais na política educacional brasileira: os casos do Ceará, Mato Grosso do Sul, São Paulo e Pará. Revista de Administração Pública, 52(6), 1179-1193. Doi: http://dx.doi.org/10.1590/0034-761220170047

Sidorkin, O., Vorobyev, D. (2018). Political cycles and corruption in Russian regions. European Journal of Political Economy, 52, 55-74. Doi: https://doi.org/10.1016/j.ejpoleco.2017.05.001

Silva, C. R. M. D., Crisóstomo, V. L. (2019). Gestão fiscal, eficiência da gestão pública e desenvolvimento socioeconômico dos municípios cearenses. Revista de Administração Pública, 53(4), 791-801. Doi: http://dx.d oi.org/10.1590/0034-761220180234

Sobel, R. S., Dutta, N., Roy, S. (2012). Does Fiscal Decentralization Result in a Better Business Climate? Applied Economics Letters, 20, 84-91. Doi: https://doi.org/10.1080/13504851.2012.657344

Suzart, J. A. S, Zuccolotto, R., Rocha, D. G. (2018). Federalismo Fiscal e as Transferências Intergovernamentais: Um Estudo Exploratório Com Os Municípios Brasileiros. Advances in Scientific and Applied Accounting, 11(1), 127-145.

Terman, J. N., Feiock, R. C. (2016). The effect of formal and informal contracting mechanisms on implementation performance in the US federalist system. Local Government Studies, 42(2), 309-331. Doi: https://doi.org/10.1 080/03003930.2015.1110522

Vicente, E. F. R., Nascimento, L. S. (2012). A efetividade dos ciclos políticos nos municípios brasileiros: um enfoque contábil. Revista de Contabilidade e Organizaçôes, 6(14), 106-126. Doi: https://doi.org/10.11606/rco.v6i14.4 5402

Vidoli, F., Fusco, E. (2018). Level of services, spatial dependence and allocative efficiency in local governments. Local Government Studies, 44(6), 848-873. Doi: https://doi.org/10.1080/03003930.2018.1512491

Vieira, M. A., Abrantes, L. A., Ferreira, M. A. M., Lopes, J. D. V. S. (2017). Implicações do esforço de arrecadação no desempenho socioeconômico dos municípios de Minas Gerais. Gestão \& Regionalidade, 33(99). Doi: https://d oi.org/10.13037/gr.vol33n99.3981

Weingast, B. R. (2006). Second generation fiscal federalism: implications for decentralized democratic governance and economic development. Available at SSRN 1153440. Doi: http://dx.doi.org/10.2139/ssrn.1153440

Winarna, J., Widagdo, A. K., Setiawan, D. (2017). Financial distress of local government: A study on local government characteristics, infrastructure, and financial condition. Global Business and Finance Review, 22, 34-47. Doi: htt p://dx.doi.org/10.17549/gbfr.2017.22.2.34 